\title{
Prevalence of nanostructure of surface layer among the bacteria Isolated from environment
}

\author{
Shila Jalalpoor \\ Lecture of Microbiology, Shahreza Branch, Islamic Azad University, and Membership of young researchers club, Iran. \\ shilla.jalalpoor@yahoo.com, jalalpour@iaush.ac.ir
}

\begin{abstract}
Nanostructure of S-layer forms the monomolecular outermost protein layer in bacteria and archaea that credited with protein or glycoprotein subunits and has crystalline biopolymer structure. This layer protects bacteria to phagocytosis and prohibits the entry of some molecules e.g. antibiotics. The premises of hospital environment can serve as reservoirs of potential pathogens. The goal of study to was investigate the Nanostructure of Surface layer among the Bacillus cereus isolates from hospital environment. The research was performed with laboratory method during 20052007 from Azzahra Hospital and Esfahan University (Isfahan province of Iran). Totally, 194 samples were collected from hospital surface. Environmental samples collected with swab in Nutrient Broth (NB). Bacterial identification was performed based on Bacteriological standard methods using selective culture medium. Samples, cultured in TSA for 16 $\mathrm{h}$, in aerobic condition were then separated for surface proteins and subjected to electrophoresis along with molecular weight marker. S-Layer in B. cereus has $97 \mathrm{KD}$ of molecular weight. From 194 bacterial isolates among hospital environment, the frequency of Bacillus sp. was $26.29 \%$. Among 13 B. cereus strains from hospital environment, only one strain $(7.69 \%)$ was the producer of S-layer. Result showed that the prevalence B. cereus strain with S-layer in hospital sensitive environment is due to increased antibiotic resistance for nosocomial infection and it is necessary to continue the reduction of transfer of virulence agent and antibiotic resistant in pathogen bacteria.
\end{abstract}

Keywords: Nanostructure of Surface Layer, Bacillus cereus, Antibiotic Resistant, Hospital Environment

Introduction

Bacillus cereus bacteria are large spore forming, Gram-positive, rod-shaped and facultative anaerobic bacteria. B. cereus strains are common in the environment and can be found in soil, dust, air, water, and on decaying materials. It has been considered as a relatively nonpathogenic opportunist commonly associated with enterotoxin mediated diarrheal food poisoning. This organism has been increasingly isolated from serious nongastrointestinal infections including endocarditis, wound infection, osteomyelitis, oral cavity associated with infected root canals, periodontal pockets, bovine mastitis, severe systemic, pyogenic infections, gangrene, septic meningitis, cellulitis, panophyhalmitis, lung abscesses, infant death, and endocarditis. Nowadays $B$. cereus regarded as one of nosocomial infections bacteria (Amaout et al., 1999; Vander Zwet et al., 2000; Hilliard et al., 2003; Washington et al., 2006). Survival spore forming bacteria on hands and environment as vegetative cells can survive for at least 24 $\mathrm{h}$, and spores survive for up to 5 months (Kamp \& Kramer, 2004).

Nosocomial infections (NIs) remain a major global concern. Overall, national prevalence rates have been described as ranging between 3.5 and $9.9 \%$. They lead to additional days of treatment, increase the risk of death, and increase treatment costs. Hospital environment have important role in NIs.

The health-care environment contains a diverse population of microorganisms. Environmental source or means of transmission of infectious agents, the presence of the pathogen does not establish its causal role; its transmission from source to host could be through indirect means, e.g., via hand transfer (Kim et al., 2000; Girard et al., 2002; Keith, 2005; Siegel \& Chiarello, 2006; Agrawal et al., 2008). The surface would be considered as one of the potential reservoirs for the pathogen, but not the de facto source of exposure. An understanding of how infection occurs after exposure, one need to conclude that the chain of infection is also important in evaluating the contribution of the environment to healthcare-associated disease. All of the following components of the chain must be operational for infection to occur: 1 . Adequate number of pathogenic organisms (dose); 2. Pathogenic organisms of sufficient virulence; 3 . A susceptible host; 4 . An appropriate mode of transmission of the organism in sufficient number from source to host; 5. The correct portal of entry into the host. Microbiologically contaminated surfaces can serve as reservoirs of potential pathogens (Kim et al., 2000; Girard et al., 2002; Keith, 2005, Agrawal et al., 2008; Siegel \& Chiarello, 2006).

Over the past 3 decades of research, it has become apparent that one of the most common surface structures on bacteria are monomolecular crystalline arrays of proteinaceous subunits termed surface layer. Nano Structure of Surface layer is attached to the outermost portion of their cell wall. It consists of a single molecular layer composed of identical proteins or glycoproteins and in electron micrographs, has a pattern resembling floor tiles (Kotiranta et al., 1998; Sara, 2001; Mesnage et al., 2001; Messner et al., 2008). The Nano Structure of Surface layer lattices can have oblique $(p 1, p 2)$ square (p4), or hexagonal (p3, p6) symmetry. Depending on the lattice type, one morphological unit consists of one, two, four, three, or six identical (glyco) protein subunits, 
respectively, and they exhibit center-to-center spacing of approximately 2.5 to $35 \mathrm{~nm}$. Most Nano Structure of Surface layer is 5 to $25 \mathrm{~nm}$ thick. It is now evident that Nano Structure of Surface layer are the most common cell surface components of pathogen bacteria such as Lactobacillus sp., Rickettsia sp., Serratia sp., Caulobacter sp., Campylobactersp., Corynebacterium, Clostridium sp. and Bacillus sp. (Kotiranta et al., 1998; Sara, 2001; Mesnage et al., 2001; Messner et al., 2008).

The Nano Structure of Surface layer has been associated with a number of possible functions, these include the following: 1-The Nano Structure of Surface layer protect bacteria from harmful enzymes (Nano Structure of Surface layer from Bacillaceae were found to function as adhesion sites for cell-associated exoenzymes) and antimicrobial agents, 2-The Nano Structure of Surface layer protect bacteria from changes in $\mathrm{pH}$, 3-The Nano Structure of Surface layer protect bacteria from attack by bacterial parasites such as Bdellovibrio bacteriovorus, and from bacteriophages, 4The Nano Structure of Surface layer can function as an adhesion, enabling the bacterium to adhere to host cells and environmental surfaces, colonize, and resist flushing, 5-The Nano Structure of Surface layer may contribute to virulence by protecting the bacterium against complement attack and phagocytosis, and 6-The Nano Structure of Surface layer may act as a as a coarse molecular sieve. Nano Structure of Surface layer can contribute to virulence when they are present as a structural component of the cell envelope of pathogens (Sara, 2000; Schaffer \& Messner, 2001; Eichler, 2003; Masahiro et al., 2003; Schaffer \& Paul, 2005; Ghorbanzadeh et al., 2011a; Ghorbanzadeh et al., 2011b). This study presents the prevalence Nano structure of Surface layer among the Bacillus cereus isolated from hospital environment. Materials and methods

\section{Sampling}

Fig. 1. Bacillus cereus on Blood Agar (top) and Selective Bacillus cereus agar (bottom)

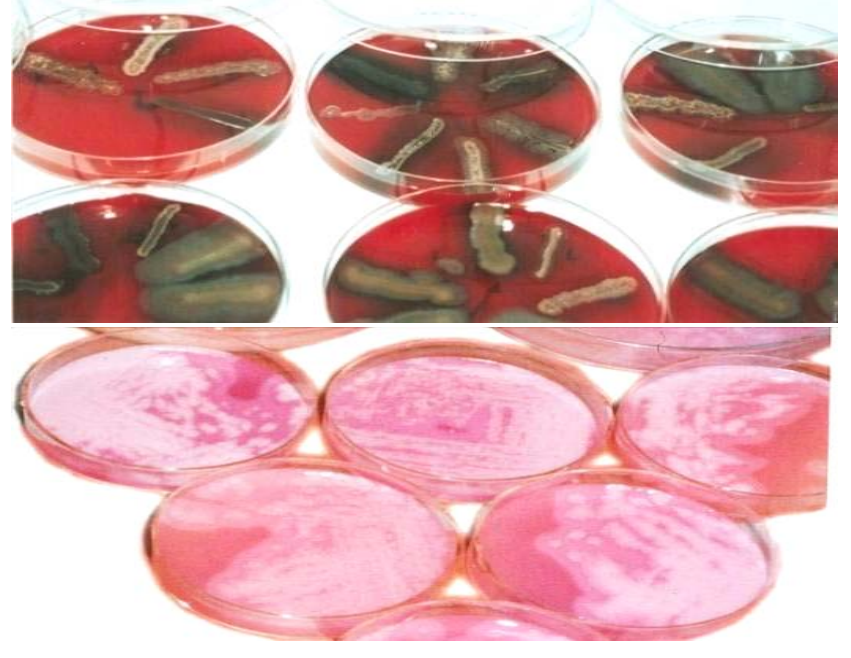

Vol. 5 No. S3 (Mar 2012)

ISSN: 0974- 6846

The research was performed with laboratory method during 2005-2007 years in Azzahra Hospital and Esfahan University. Overall study 194 sample from hospital environment. Hospital environment samples were randomly collected from high and low hospital contact surfaces with swab (Effective sampling of surfaces requires moistened swabs) in Tryptone Soya Agar (Merck) (Jalalpoor et al., 2007; Sehulster \& Raymond, 2003).

\section{Bacterial strains}

Specimen grows on sheep blood and chocolate agars incubated at $37^{\circ} \mathrm{C}$ under aerobic conditions. Gram stains from blood cultures Bacillus as Gram-positive bacilli, intracellular and cell-free spores do not stain by the Gram technique but may be visualized with the malachite green stain, the spores will appear green. On SBA, colonies of $B$.cereus usually large, with a matte or granular texture, and most strains are beta hemolytic. The strains were identified based on colony morphology, Gram stain reaction, spore formation, and biochemical tests with the BioMerieux database system (Figure 1) (Washington et al., 2006; Jalalpoor et al., 2007).

\section{Detection Nano Structure of Surface layer}

For the examination of surface proteins, $16 \mathrm{~h}$ old bacterial cells cultured on TSA enriched with $0.6 \%$ yeast extract were collected from the agar plates, washed once in phosphatebuffered saline (PBS) $(\mathrm{pH}$ 7.4), and suspended in the same buffer; the cell suspensions were adjusted to standard optic density; optical density of 0.6 $(450 \mathrm{~nm})$. Equal volumes $(4 \mathrm{ml})$ of the cell suspensions were centrifuged $(3,000 \mathrm{~g}$ in $6 \mathrm{~min})$. The pellets were resuspended in $500 \mathrm{ml}$ of $1 \%$ sodium dodecyl sulfat (SDS)-Tris- $\mathrm{HCl}(\mathrm{pH} 8$ ) and shaken for $30 \mathrm{~min}$ at RT. After centrifugation, the supernatants were boiled for $5 \mathrm{~min}$ in sample buffer (60 mM Tris- $\mathrm{HCl}, 1 \%$ SDS, $10 \%$ glycerol, $1 \%$ mercaptoethanol, and $0.0005 \%$ bromophenol blue) (Kotiranta et al., 1998, Kotiranta et al.,1999) and analyzed

Fig. 2. SDS PAGE of surface proteins in B.cereus strains Lane 1: Myosin 206 kDa-Betagalactosidase 117 kDa- BSA $80 \mathrm{kDa}$ - Ovalbumin, $40 \mathrm{kDa}$ and Lane 2: B.cereus strains isolated from hospital environment

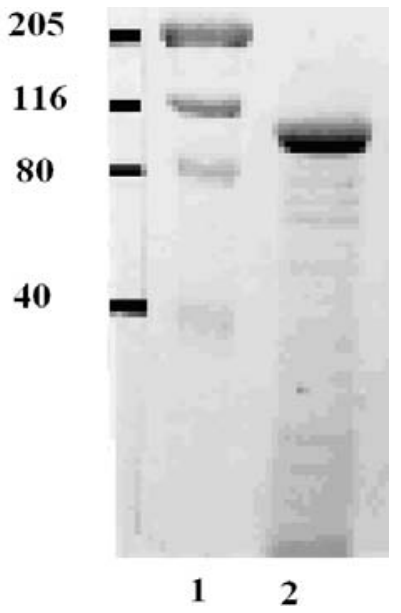

Research article "Proceedings of The First Nano Biotechnology Conference held in Damghan branch, Islamic Aazad University, Damghan, Iran during 26" May 2011" CIndian Society for Education and Environment (iSee) 
by SDS- $10 \%$ polyacrylamide gel (PAGE) electrophoresis (Sambrook \& Russel, 2001).

\section{Statistical analyses}

All the statistical analyses were carried out using SPSS version 14. Chi-Square and fisher test used for determination of significance of association. The $p \leq 0.05$ was considered significant.

Results

Based on the results obtained from 194 samples, frequency of Bacillus cereus strains on hospital surfaces was $6.7 \%$. Based on the results of SDS-PAGE, 1 (7.69\%) of the studied bacteria ( $B$. cereus strain) was the Nano Structure of Surface layer producer and 12 (92.31\%) lacked the ability to produce Nano Structure of Surface layer (Fig.1). Fig. 2. shows the SDS PAGE of surface proteins in B.cereus strains. Fig. 3. represents the frequency Nano Structure of Surface Layer among the $B$. cereus strains isolated from hospital environment Discussion

Fig. 3. Frequency Nano Structure of Surface Layer among the Bacillus cereus strains isolated from hospital

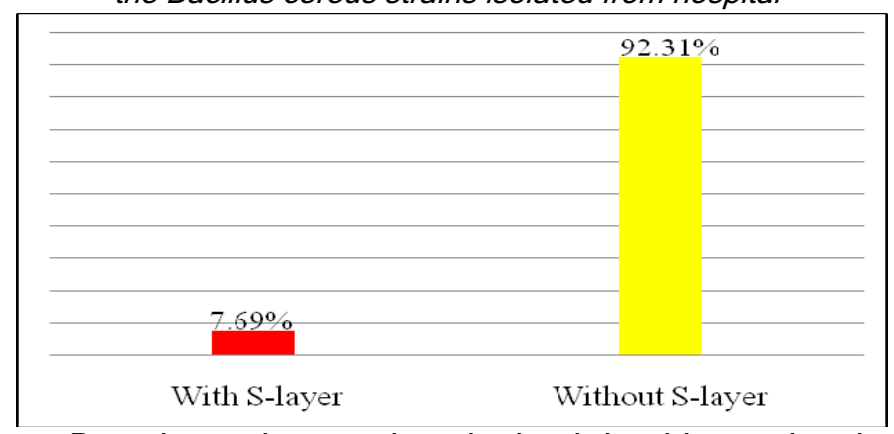

Based on the results obtained in this study, the frequency of Bacillus cereus strains on hospital surfaces was $6.7 \%$. Earlier investigators also reported Bacillus spp. as abundant isolates of hospital surface (24\%) (Jalalpoor et al., 2010a,b,c,d). Earlier studies on four strains of Bacillus cereus isolated from clinical samples revealed that they could produce Nano Structure of Surface layer while the standard counterpart strains could not have produced Nano Structure of Surface layer (Kotiranta et al., 1998; Kotiranta et al., 1999).

Based on the results obtained in the present study, 1 $(7.69 \%)$ of the strain isolated from hospital surfaces was the Nano Structure of Surface layer producer. Also, similar published studies indicate for the spread of Bacillus cereus strains resistant to antibiotics in hospitals. The lack of bacterial population control, leads to rapid release of antibiotic resistance from resistance strains to sensitive strains and ultimately leading to the spread of antibiotic resistance of nosocomial infections in hospitals and the community (Jalalpoor et al., 2009a,b; Jalalpoor et al., 2010a).

Approximately one third of nosocomial infections are preventable. Cleaning is the necessary first step of any sterilization or disinfection process. Cleaning may involve the removal of organic matter, salts, and visible soils, all of which interfere with microbial inactivation.

Environmental surfaces carry the least risk of disease transmission and can be safely decontaminated using less rigorous methods than those used on medical instruments and devices. Isolation precautions are designed to prevent transmission of microorganisms by common routes in hospitals. Because agent and host factors are more difficult to control, interruption of transfer of microorganisms is directed primarily at transmission (Sara \& Uwe, 2000; Madani et al., 2009; Mielke, 2010).

\section{Acknowledgments}

Author would like thank their subspecialty Alzahra Hospital Management, Isfahan University, Management of science research lab of Isfahan University (Iran).

\section{References}

1. Agrawal P, Ghosh AN, Kumar S, Basu B and Kapila K (2008) Prevalence of extended-spectrum betalactamase among Escherichia coli and Klebsiella pneumoniae isolates in a tertiary care hospital. Indian J. Path. Microbiol. 51,137-42.

2. Amaout MK, Tamburro RF and Bodner SM (1999) Bacillus cereus causing fulminal sepsis and hemolysis in two patients with acute leukemia. Pediatr. Hematol. Oncol. 21, 431-5.

3. Eichler J (2003) Facing extremes: archaeal surfacelayer (glyco) proteins. Microbiol. 149, 3347- 3351.

4. Ghorbanzadeh V, Moshtaghian SJ, Habibian S and Ebadi AG (2011a) Influence of Nano-Silver on Graffian Follicles via Intraperitoneal Injection in Rats. Middle-East J. Sci.Res. 8(1), 228-230.

5. Ghorbanzadeh V, Moshtaghian SJ, Habibian S and Ebadi AG (2011b) Influence of Nano-Silver on primary follicles of ovary via intraperitoneal injection in rats. World J. Zool. 6(2), 215-216.

6. Girard R, Perraud M, Pruss A, Savey A, Tikhomirov E, Thuriaux M and Vanhems $P$ (2002) Prevention of hospital-acquired infections, A practical guide, Department of Communicable Disease, Surveillance and Response, Editors; Ducel G, Fabry j, Nicolle L, 2nd edition, Available at WHO/CDS/CSR/EPH/2002.12.

7. Hilliard NJ, Schelonka RL and Waites KB (2003) Bacillus cereus bacteremia in a preterm neonate. $J$. Clin. Microbiol. 41, 3441-3444.

8. Jalalpoor S, Kasra Kermanshahi R, Nouhi AS and Zarkesh H (2010b) Survey Frequence of $\beta$-lactamase Enzyme and Antibiotic Sensitivity Pattern in Isolated Pathogen Bacteria from Low and High Hospital Contact Surfaces. Pajuhandeh J. 15(2), 77-82.

9. Jalalpoor S, Kasra Kermanshahi R, Nouhi AS and Zarkesh Esfahani (2009d) Antibiotic Resistance in B.cereus st. Isolated from Staff Hands and Hospital Surfaces. Third Iranian Congress of Clinical Microbiology, Iran.

10. Jalalpoor S, Kasra Kermanshahi R, Nouhi AS and Zarkesh Esfahani H (2009c) The comparative 
frequency the $\beta$-lactamase Production and antibiotic susceptibility pattern of Bacterial stains isolated from Staff Hands and Hospital Surfaces in Azzahra Hospital-Isfahan. Iran. J. Med. Microbiol. 3(4), 37-45.

11. Jalalpoor S, Kasra Kermanshahi R, Nouhi AS and Zarkesh Esfahani H (2010a) Survey Characterization Nano Structure Surface Layer in Some of Pathogen Bacteria. Zahedan J. Res. Med. Sci. 23(4), 470-477.

12. Jalalpoor $S$, Kasra Kermanshahi R, Nouhi AS and Zarkesh Isfahani H (2009b) Survey effect of in-vivo and in-vitro condition on expression of surface layer genes in bacteria. J. Iran. Chem. Soc. 6 (Suppl), S11.

13. Jalalpoor S, Kasra Kermanshahi R, Nouhi AS and Zarkesh Isfahani H (2009a) The Prevalence of Nanostructure Surface Layer in Bacillus Cereus Strains Isolated from Staff Hands and Hospital Surfaces. J. Isfahan Med. School, 27(100), 632-645.

14. Jalalpoor S, Kermanshahi KR, Nouhi $A$ and Zarkesh $\mathrm{H}$ (2007) Study of $\beta$-lactamase and S-layer Production in some of Isolated Pathogen Bacteria From Clinical and Environmental Hospital Samples. MSc thesis,Iran, Tehran, Islamic Azad University Science and Research Branch Tehran, Iran.

15. Kamp G and Kramer A (2004) Epidemiologic Background of Hand Hygiene and Evaluation of the Most Important Agents for Scrubs and Rubs. Clin Microbiol. Rev. 17(4), 863-93.

16. Keith SK (2005) ICDR01-0204: Multidrug Resistant Bacteria: Mechanisms of Resistance, Epidemiology and Prevention. Virgo Publishing, Infection Control Education Institute, PP.1-10.

17. Kim JM, Park ES, Teong TS, Kim KM and Kim TM (2000) Multicentre surveillance study for nosocomial infections in major hospitals in Korea. Nosocomial Infection Surveillance Committee of the Corean Society for Nosocomial Infection Control. Am. J. Infect. Control, 28(5), 454-458.

18. Kotiranta A, Haapasalo M and Kari K (1998) Surface Structure, Hydrophobicity, Phagocytosis , and Adherence to Matrix Proteins of Bacillus cereus cells with and without the Crystalline Surface Protein Layer. Infect. Immun. 66(10), 4895-4902.

19. Kotiranta AK, Hitoshi I, Markus P, Haapasalo P and Kari L (1999) Radiation sensitivity of Bacillus cereus with and without a crystalline surface protein layer. FEMS Microbiol. Lett.179, 275-280.

20. Madani N, Rosenthal VD, Dendane T, Abidi K, Zeggwagh AA, Abouqal R (2009) Healthcareassociated infections rates, length of stay, and bacterial resistance in an intensive care unit of Morocco: findings of the International Nosocomial Infection Control Consortium (INICC). Int. Arch. Med. 2(29), 1-7.

21. Masahiro $\mathrm{Y}$, Hirofuji $\mathrm{T}$, Motooka $\mathrm{N}$, Nozoe $\mathrm{K}$, Shigenaga $\mathrm{K}$ and Anan H (2003) Humoral Immune Responses to S-layer-Like Proteins of Bacteroides
Vol. 5 No. S3 (Mar 2012)

ISSN: 0974- 6846

forsythus. Clin. Diagnost. Laborate. Immune.10(3), 383-387.

22. Mesnage S, Haustant $M$ and Foue A (2001) A general strategy for identification of S-layer genes in the Bacillus cereus group :molecular characterization of such a gene in Bacillus thuringiensis subsp. galleriae NRRL 4045. J Microb.147,1343-51.

23. Messner $P$, Steiner $K$, Zarschler $K$ and Schaffer $C$ (2008) S-layer nanoglycobiology of bacteria. Carbohydr. Res. 343(12),1934-51.

24. Mielke M (2010) Prevention and control of nosocomial infections and resistance to antibiotics in Europe - Primum non-nocere: elements of successful prevention and control of healthcare-associated infections. Int. J. Med. Microbiol.300(6), 346-50.

25. Sambrook J and Russell DW (2001) Molecular Cloning: A Laboratory Manual, 3rd Edition. Cold Spring Harbor,NY: Cold Spring Harbor Laboratory Press.

26. Sara M (2001) Conserved anchoring mechanisms between crystalline cell surface S-layer proteins and secondary cell wall polymers in Gram-positive bacteria. Trends Microbiol. 9, 47-9.

27. Sara M and Uwe B (2000) Sleytr.S-layer Proteins. J Bacteriol.182(4), 859-68.

28. Schaffer C and Messner P (2001) Glycobiology of surface layer proteins. Biochimie.83, 591-99.

29. Schaffer $C$ and Paul M (2005) The structure of secondary cell wall polymers: how Gram-positive bacteria stick their cell walls together. Microbiol.15, 643-651.

30. Sehulster L and Raymond YW (2003) Guidelines for Environmental Infection Control in Health-Care Facilities. U.S. Department of Health and Human Services Centers for Disease Control and Prevention (CDC).Atlanta GA 30333.

31. Siegel JD and Chiarello L (2006) Management of Multidrug-Resistant organisms in Healthcare Settings, CDC.4-23. Available at http://www.cdc.gov/ncidod/dhqp/pdf/ar/ mdroGuideline 2006pdf. Accessed 1.1. 2001.

32. Vander Zwet WC, Parlevliet GA, Savelkoul PH, Stoof $\mathrm{J}$ and Kaiser AM (2003) Outbreak of Bacillus cereus infection in a neonatal intensive care unit traced to balloons used in manual ventilation. J. Clin. Microbiol. 38, 4131-6.

33. Washington C, Stephen A, Janda W, Koneman E, Procop G, Schreckenberger P and Woods G (2006) Koneman's Color Atlas and Textbook of Diagnostic Microbiology, Sixth edition.USA: Lippincott wiiliams \& wilkins, pp: 775-9. 